\title{
Contribución de las reacciones de aglutinación al diagnóstico de fiebre tifoidea
}

\author{
Aldo Bancalari*, Antonio Banfi*.
}

En Chile una de las enfermedades que destacan por su altísima morbilidad es la fiebre tidoidea, la cual ha tenido un notorio repunte en los últimos años. ${ }^{1}$ Desde 1896 , en que $\mathrm{Widal}^{2}$ desarrolló la técnica del serodiagnóstico en tifoidea, este test es usado ampliamente en el diagnóstico diferencial de fiebre tifoidea. En algunas oportunidades, como es la situación de los pacientes ambulatorios, es el examen decidor para confirmar o refutar el diagnóstico de esta enfermedad. Sin embargo, algunos investigadores ${ }^{3,4}$ han puesto en duda el verdadero valor de las reacciones de aglutinación, basados en el hecho de observar un alto porcentaje de títulos elevados, falsamente positivos y en otras oportunidades falsamente negativos, dificultando enormemente su interpretación. En el año 1952, Viel y cols. ${ }^{5}$ insinúan que es necesario estudiar la sensibilidad de los antígenos y de la técnica misma de la reacción de Widal al encontrar un número significativo de pacientes con coprocultivo positivo y test de Widal negativo. En la discusión del mismo trabajo ${ }^{5}$ los profesores Alessandri y Armas-Cruz también objetan el verdadero valor de las reacciones de Aglutinación.

El test de Widal mide los anticuerpos aglutinantes para los antígenos somáticos $\mathrm{O}$ y flagelar $\mathrm{H}$ de la Salmonella typhi, considerándose tradicionalmente positiva un alza del título único cuyo valor sea mayor de 1:50 ó 1:100 tomado en la primera, segunda o tercera semana de enfermedad. ${ }^{6,7}$ El título del antígeno $\mathrm{H}$ es de poco valor en el diagnóstico de fiebre tifoidea, puesto que puede aumentar en forma inespecífica en otros cuadros infecciosos. ${ }^{6,8}$ El objetivo del presente

*Hospital Luis Calvo Mackenna. estudio ha sido revisar el comportamiento de las reacciones de aglutinación en el curso del período de estado de la fiebre tifoidea.

\section{MATERIAL Y METODO}

Se estudiaron 104 pacientes con fiebre tifoidea, 59 de sexo masculino y 45 de sexo femenino, entre 2 y 15 años de edad, admitidos al Hospital Luis Calvo Mackenna, entre los años 1970 y 1976. Previo a su ingreso, los niños tenían 5 a 12 días de evolución febril, y en ellos se realizaron los siguientes exámenes: Hemograma; Velocidad de Sedimentación; Hemocultivos seriados y Reacciones de Aglutinación al primero y décimo día de hospitalización.

La confirmación diagnóstica para todos los casos se basó en uno o más hemocultivo positivo para Salmonella typhi.

El test de Widal se realizo haciendo previamente una reacción de aglutinación en lámina, reacción de tipo cualitativo; y luego aquellas muestras que dieron una aglutinación en lámina positiva, se sometieron a un análisis cuantitativo en tubo. Los antígenos utilizados fueron los que prepara el Instituto Bacteriológico de Chile.

Se consideró reacción de Aglutinación positiva aquella que tenía un título para el antígeno somático 01/100 o mayor en cualquiera de las dos muestras analizadas. Además se estimó como seroconversión cuando el título del segundo test de Widal era el doble del primero. Paralelamente se estableció como título estable aquel que no se modificó en ninguna de las dos reacciones de aglutinación. Por último se consideró título descendente aquel que disminuyó en la mitad o hasta cero en la segunda reacción analizada. 
El estudio de las reacciones de aglutinación demostró positividad en 60 pacientes $(57,7 \%)$ y negatividad en $44(42,3 \%)$. (Tabla 1 .)

Tabla 1

Fiebre tifoidea. Estudio reacciones aglutinación Hospital Luis Calvo Mackenna 1970-1976

104 casos

\begin{tabular}{lcc}
\hline Reacciones de Aglutinación & Casos & $\%$ \\
\hline Positivas & 60 & 57,7 \\
\hline Negativas & 44 & 42,3 \\
\hline TOTAL & 104 & 100
\end{tabular}

En las reacciones de aglutinación positiva se observó seroconversión en 31 casos $(28,8 \%)$, mientras que en 11 niños $(10,6 \%)$ el título fue estable, y en 18 enfermos (18,3\%) éste fue decreciente. En este último grupo se incluyen 4 pacientes que negativizaron totalmente su reacción para el antígeno somático $\mathrm{O}$. (Tabla 2.)

Tabla 2

\section{Fiebre tifoidea. Estudio reacciones aglutinación Hospital Luis Calvo Mackenna 1970-1976 \\ 104 casos}

Reacciones de Aglutinación
Positiva

\begin{tabular}{lcc}
\hline $\begin{array}{l}\text { Título creciente } \\
\text { (seroconversión) }\end{array}$ & 31 & 28,8 \\
\hline Título estable & 11 & 10,6 \\
\hline Título decreciente & 18 & 18,3
\end{tabular}

De los niños, 60 con test de Widal + , en $16(26,6 \%)$ se observaron reacciones cruzadas.

De los 60 casos analizados con reacción positiva de aglutinación, en $16(26,6 \%)$ hubo reacciones cruzadas para dos o más antígenos.
En Chile el grado de infección por salmonellas es muy elevado, comprobándose en un estudio de pesquisa de anticuerpos antisalmonellas realizado por Prado y col. ${ }^{9}$ un $57,4 \%$ y un $41,7 \%$ de reacciones positivas en adultos y niños de población sana, respectivamente. Estos hechos son concordantes con los resultados del presente estudio, destacando en especial el alto porcentaje de reacciones cruzadas, $26,6 \%$. Es necesario recordar que las salmonellas se dividen en distintos grupos serológicos en base al antígeno somático $\mathrm{O} .{ }^{10} \mathrm{El}$ grupo $\mathrm{D}$ comprende 78 serotipos de salmonellas, una de las cuales es la Salmonella typhi; compartiendo todos los organismos de este grupo los antígenos 09, 012 y 059..$^{6}$ Además del grupo D, las salmonellas grupos A y B también poseen el antígeno 012, pudiendo esta comunidad antigénica crear una gran cantidad de reacciones cruzadas. ${ }^{6}, 11$ Debido a que en nuestro medio las infecciones por salmonellas más frecuentes son las producidas por la $\mathrm{S}$. typhi y otras del grupo B y E, ${ }^{9}$ resulta evidente que la interpretación de las reacciones de aglutinación puede ser equívoca y de este modo no contribuir al diagnóstico de tifoidea.

Es también digno de destacar el número importante de reacciones de título estable, 11 niños $(10,6 \%)$ y de título decreciente, 18 casos $(18,3 \%)$, en especial en este último aspecto, puesto que 4 pacientes negativizaron hasta llegar a cero sus títulos de antigeno $O$. Este comportamiento de las reacciones de aglutinación es difícil de explicar debido a que ninguno de los enfermos estudiados tenía más de 12 días de evolución, y el segundo test de Widal se efectuó a los 10 días después de su ingreso (tercera semana de enfermedad), período en que se observa la mayor positividad de la reacción de Widal. ${ }^{12}$

Por otra parte, ${ }^{13}$ se ha demostrado en voluntarios humanos que no hay diferencias de título en la reacción de Widal entre pacientes tratados precozmente y pacientes no tratados. Esto disminuiría la importancia que se ha atribuido al uso precoz de antibióticos en fiebre tifoidea, en el sentido de disminuir la respuesta inmunológica.

Las dudas que plantean las reacciones de aglutinación respecto de su real valor han sido motivo para realizar diversas investigaciones. Sen y Saxena, ${ }^{14}$ en un estudio de 451 casos de fiebre tifoidea, encuentran que un solo test de 
Widal puede conducir a menudo a un diagnóstico equivocado. Paralelamente Schröeder ${ }^{6}$ concluye que las reacciones de aglutinación son inespecíficas, mal estandarizadas y difíciles de interpretar correctamente. Wicks y cols. ${ }^{4}$ observan en pacientes con hemocultivo positivo para Salmonella typhi un $34,6 \%$ de reacciones de aglutinación negativas.

Las razones por las cuales una reacción de Widal puede ser negativa o dar información errónea son numerosas, entre las cuales se pueden destacar (Tabla 3):

\section{Tabla 3}

\section{Factores de error en la reacción de Widal}

1. Test inmunológico: estandarización cuidadosa.

2. Comunidad antigénica de Salmonellas: S. grupo A, B y $\mathrm{D}$ poseen en común Ag. $\mathrm{O}_{12}$.

3. Formación de Anticuerpos inespecificos no inducidos por Salmonellas: Hepatitis Crónica Activa, Tuberculosis, Enfermedad de Hodgkin, etc.

4. Desconocimiento de títulos normales en zonas endémicas y no endémicas.

5. Falla en la respuesta del huésped:

- Dosis infectante mínima.

- Falta de contacto entre germen y sistema inmunologico.

- Defecto inmunológico.

6. Inoculación previa de vacuna antitífica y/o episodio anterior de fiebre tifoidea.

a) Es un test inmunológico y como tal debe ser hecho en condiciones cuidadosamente estandarizadas. Los antígenos utilizados pueden ser inestables o bien los controles dudosos, y de este modo confundir la interpretación de la reacción. DeVillier y col. ${ }^{15}$ comparan cuatro antígenos anti-Salmonella typhi preparados en diferentes laboratorios, encontrando diferencias dos a cuatro veces del título de la reacción de Widal en el suero del mismo enfermo.

b) El hecho de que todas las Salmonellas estén relacionadas entre $s^{16}$ desde el punto de vista antigénico (comunidad antigénica), determina un nuevo factor de error.

c) Formación de anticuerpos inespecíficos no inducidos por Salmonella, que dan falsas reacciones positivas. Se ha señalado en casos de hepatitis crónica activa, tuberculosis, enfermedad de Hodgkin, linfosarcoma, etc., 5,17 la presencia de estos anticuerpos inespecíficos. d) Es necesario estudiar los títulos de anticuerpos anti-Salmonellas en poblaciones endémicas y no endémicas para poder establecer un nivel basal o general, $y$ de esa forma poder deducir el título diagnóstico real. En nuestro país el único estudio efectuado es el de Prado y col. $^{9}$ en el área Oriente de Santiago, que demuestra que las Salmonellas que con mayor frecuencia infectan a nuestra comunidad son la Salmonella typhi, Salmonella london, Salmonella newington y Salmonella typhimurium, lo que indica que es necesario introducir modificaciones en la reacción de Widal, en el sentido de incluir en ella los Antígenos correspondientes a estas Salmonellas que tienen una marcada difusión en nuestro país. Además sería necesario medir los títulos en pacientes con procesos febriles no tíficos que pueden dar reacciones anamnésicas.

e) La reacción de aglutinación puede ser negativa o de título bajo debido a una dosis infectante pequeña; también a la falta de contacto entre la Salmonella y el sistema productor de anticuerpos, por ejemplo líquido articular; o bien a defectos inmunológicos del huésped.

f) La inoculación previa de vacuna antitífica o un episodio anterior de fiebre tifoidea pueden tornar de escaso valor el test de Widal.

El diagnóstico definitivo de tifoidea se apoya en el cuadro clínico y en el aislamiento de Salmonellas en el hemocultivo, mielocultivo o roséola. ${ }^{18}, 19 \mathrm{La}$ reacción de Widal a nuestro juicio la mayoría de las veces no contribuye al diagnóstico de la enfermedad, creando mucha confusión y por ende mal manejo de pacientes con fiebre tifoidea.

En el período de estada de la fiebre tifoidea son los hallazgos clínicos unidos a los resultados muy constantes de la serie blanca del hemograma y de la velocidad de sedimentación, los que hacen sostener el diagnóstico clínico de fiebre tifoidea. ${ }^{20}$

Sería necesario extender el empleo del hemocultivo a nivel de consulta externa para obtener mejoría del diagnóstico etiológico en tifoidea. La respuesta inmunológica inducida por las Salmonellas, y que se evidencia a través de las reacciones de aglutinación, continúa aportando elementos de juicio equívocos y esto hace necesario sugerir que su empleo "rutinario" sea evitado. 


\section{RESUMEN}

Se estudia el comportamiento del test de Widal en el periodo de estado de la fiebre tifoidea.

Se analizan 104 pacientes con hemocultivos positivos para Salmonella typhi, con 5 a 12 días de evolución febril.

El $42,3 \%$ de los nin̄os con tifoidea presentaron reacciones de aglutinación negativas.

De las reacciones positivas $(57,7 \%)$, el $28,8 \%$ correspondió a seroconversión, siendo el resto de título estable o decreciente.

Se enumeran algunas de las razones por las cuales el test de Widal pueda dar información errónea.

Se concluye que las reacciones de aglutinación tienen poca utilidad en el diagnóstico de fiebre tifoidea, haciéndose hincapié en la importancia de los hallazgos clínicos, serie blanca del hemograma y VHS para formular el diagnóstico de tifoidea.

Con el fin de mejorar la pesquisa etiológica en tifoidea, se propone extender el uso del hemocultivo a consulta extema.

\section{SUMMARY}

The Widal Test was done in 104 consecutive bacteriologically proven typhoid fever paediatries patients. Duration of the fever ranged between 5 and 12 days.

Only $57,7 \%$ of patients showed a positive Widal Test defined by a 0 agglutinin of 1:100 or higher. $28,8 \%$ of all positive reactions had rising titer of agglutinins. The others positive tests had decreasing or stable titer.

The various factors which can yield the Widal Test unreliable are discussed. Stress should be made mainly on clinical and hematological founds rather than serological tests in the diagnostic approach to typhoid fever.

\section{REFERENCIAS}

1 Vigilancia de enfermedades transmisibles y zoonosis. Publicacion mensual, Chile, Vol. V, N. ${ }^{\circ} 1,1978$.

2 Nicalle, M. M. C. y Halipré, A. Sèriodiagnostic de la fièvre typhoide à-propos d'une modification par Widal F. Bull Soc. Med. Hop. París 13: 561, 1896.

3 Stuart, B. M. y Pullen, R. L. Typhoid: Clinical analysis of three hundred and sixty cases. Arch. Intern. Med. 78: $629,1946$.

4 Wicks, A. C. B.; Holmes, G. S. y Davidson, L. Endemic
Typhoid Fever, a diagnostic pitfall. Q. J. Med. 40: 341, 1971

5 Viel, B. y Aste, G. Coprocultivo en enfermos de fiebre tifoidea tratados con Cloramfenicol. Rev. Méd. Chile, 80 $399,1952$.

${ }^{6}$ Schröeder, S. A. Interpretation of Serologic Test for Typhoid Fever. JAMA 206: 839, 1968.

7 Wilson, G. S. y Miles, A. A. Topley and Wilson's Principles of Bacteriology and Immunity, ed. 5. Baltimore, Williams \& Wilkins Co., 1964, p. 1848.

${ }^{8}$ Huckstep, R. L. Typhoid Fever and Other Salmonellease Infections. Edinburgh and London, E. \& S. Livingstone Ltd., 1962, p. 84.

9 Prado, V.; Vilches, A.; Eismendi, C.; Ponce, R.; Pozo, E.; Reyes, C.; Schwartz, R.; Simha, R.; Vicuña, L. y Vilca, D. Indice de infección por Salmonella en población del Area Oriente de Santiago. Rev. Méd. Chile, 102: 683, 1974

${ }^{10}$ Edwards, P. R. y Erwing, W. H. Identification of Enterobacteriaceae, ed. 2, Minneapolis, Burges Publishing Co., 1962.

11 Reynolds, D.W.; Carpenter, L.R. y Simon,W.H. Diagnostic Specificity of Widal's Heaction for Typhoid Fever. JAMA, 214: 2192, 1970 .

12 Borgoño, J. M. y Pearson, E. Fiebre Tifoidea y Paratifoidea Análisis clínico y de laboratorio de un brote estacional Rev. Méd. Chile, 93: 145, 1965.

${ }^{13}$ Hornick, R. B.; Greisman, S. E.; Woodward, T. E.; DuPont, H. D,; Dawkins, A. T. y Snyder, M. J. Thyphoid Fever: Pathogenesis an Immunologic Control. N. Engl. J. Med. 282: $686,1970$.

${ }^{14}$ Sen, $R$. y Saxena, S. N. A critical assessment of the convertional Widal test in a diagnosis of typhoid and paratyphoid fever. Indian J. Med. Res. 57: 1, 1969.

${ }^{15}$ DeVillier, A. B.; Deupree, R. H.; Dickinson, C. y Beeler, M. F. Amer. J. Clin. Path. 44: 410, 1965.

${ }^{16}$ Krugman, S. y Ward, R. Enfermedades Infecciosas Infantiles. México, Editorial Interamericana, S. A., 1970, p. 289.

17 Protell, R. L.; Soloway, R. D.; Martin, W. J.; Schoenfield, L. J. y Summerskill, W. H. J. Antisalmonella agglutinins in chronic active liver disease. Lancet 2: 330, 1971.

18 Christie, A. B. Infectious Diseases: Epidemiology and Clinical Practice. Edinburg, 1974, p. 108.

${ }^{19}$ Gilman, R. H.; Terminel, M.; Levine, M. M.; HerndindezMendoza, P. y Hornick, R. B. Relative Efficacy of Blood Urine, Rectal Swab, Bone-Marrow and Rose Spot Cultures for Recovery of Salmonella Typhi in Typhoid Fever. Lancet, $1,1211,1975$.

20 Bancalari, A. y Banfi, A. Fiebre Tifoidea: Experiencia en 831 casos Pediátricos. Rev. Méd. Chile, 106: 609, 1978. 